\title{
The effect of landscape on Cucurbita pepo-pollinator interaction networks varies depending on plants' genetic diversity
}

\author{
Patricia Landaverde-González ${ }^{1,2}$ (D) Eunice Enríquez ${ }^{2}$ (D) J Juan Núñez-Farfán ${ }^{3} \mathbb{D}$
}

Received: 28 January 2021 / Accepted: 25 September 2021 / Published online: 12 October 2021

(c) The Author(s) 2021

\begin{abstract}
In recent years, evidence has been found that plant-pollinator interactions are altered by land-use and that genetic diversity also plays a role. However, how land-use and genetic diversity influence plant-pollinator interactions, particularly in the Neotropics, where many endemic plants exist is still an open question. Cucurbita pepo is a monoecious plant and traditional crop wide distributed, with high rates of molecular evolution, landraces associated with human cultural management and a history of coevolution with bees, which makes this species a promising model for studying the effect of landscape and genetic diversity on plant-pollinator interactions. Here, we assess (1) whether female and male flowers differences have an effect on the interaction network, (2) how C. pepo genetic diversity affects flower-bee visitation network structure, and (3) what is the effect that land-use, accounting for C. pepo genetic variability, has on pumpkin-bee interaction network structure. Our results indicate that female and male flowers presented the same pollinator community composition and interaction network structure suggesting that female/male differences do not have a significant effect on network evolution. Genetic diversity has a positive effect on modularity, nestedness and number of interactions. Further, the effect of semi-natural areas on nestedness could be buffered when genetic diversity is high. Our results suggest that considering genetic diversity is relevant for a better understanding of the effect of land-use on interaction networks. Additionally, this understanding has great value in conserving biodiversity and enhancing the stability of interaction networks in a world facing great challenges of habitat and diversity loss.
\end{abstract}

Keywords Wild bees $\cdot$ Landscape heterogeneity $\cdot$ Neotropics $\cdot$ Observed heterozygosity $\cdot$ Allele richness

Handling Editor: Christina Mogren and Heikki Hokkanen.

Patricia Landaverde-González

patylandavr@gmail.com

1 General Zoology, Institute for Biology, Martin-Luther University Halle-Wittenberg, Hoher Weg 8, 06120 Halle (Saale), Germany

2 Unidad para el Conocimiento, Uso y Valoración de la Biodiversidad, Centro de Estudios ConservacionistasCECON-, Facultad de Ciencias Químicas y Farmacia, Universidad de San Carlos de Guatemala, Guatemala, Guatemala

3 Laboratorio de Genética Ecológica y Evolución, Departamento de Ecología Evolutiva, Instituto de Ecología, Universidad Autónoma de México, AP 70-275, 04510 Distrito Federal, Mexico

\section{Introduction}

Land use change, principally habitat loss and fragmentation, has been signalled to alter plant-pollinator interactions by affecting species survival, species distributions, species phenologies and changing the complex set of relationships between plants and pollinators suggesting that plant-pollinator interactions may be more susceptible to global change than previously thought (Alves Ferreira et al. 2013). However, despite recent advances, it is still not understood how land-use and climate change influence plant-pollinator interactions (Dalsgaard 2020) principally in the Neotropics that is considered a hotspot of diversity and origin of cultivated plants (Khoury et al. 2016).

One of these endemic cultivated plants is Cucurbita pepo ssp. pepo that is a major crop of worldwide economic importance, as it is cultivated and consumed globally (Paris 2016). In Mesoamerica, C. pepo species are important ecological elements of the milpa traditional management 
system (cultivation of maize alongside beans, and one or two additional Cucurbita species; Aguilar et al. 2003; OECD 2012) preventing weeds and soil erosion, maintaining soil moisture and biodiversity of mammals and insect pollinators (Gliessman 1983; Lozada-Aranda et al. 2017; LandaverdeGonzález et al. 2017). Cucurbita pepo is the best-studied cultivated crop (Paris et al. 2003, 2012) and considered the most diverse species in the genus (Gong et al. 2013; Paris 2016). Furthermore, the exceptionally high rates of molecular evolution of the genus, the local genetic structure and morphological differentiation of certain domesticated Cucurbita landraces have been associated with differences among human cultural management (Casas et al. 2007; Sanchez-de la Vega et al. 2018; Enríquez et al. 2018) and geographical and climatic processes (Castellanos-Morales et al. 2019). Further, it has been suggested a process of coevolution between Cucurbita and their main pollinators due to the congruence in divergence time of most wild taxa and specialized bees of the genera Xenoglossa and Peponapis. Thus, this system is a promising model for studying evolution of plant-pollinators interactions (Castellanos-Morales et al. 2018).

Cucurbita pepo is a monoecious plant with spatial separation of female and male flowers. C. pepo subsp. texana has displayed differential inbreeding depression between male and female traits (Hayes et al. 2005). Furthermore, herbivore damage to flowers of $C$. pepo increased the floral fragrance of male but not in female flowers, suggesting that external environmental conditions may be critical for the resulting interactions between plants, herbivores, and pollinators (Theis et al. 2009). Yet, changes of temperature can induce femaleness when it is colder or maleness when it is warmer (Wien et al. 2002). Hence, the understanding of the effect that landscape can have on C. pepo female and male flowers and their differential interactions with pollinators is an open question that can help to understand the dynamics of evolution in domesticated plants.

Complex and genetically based, contributing to community diversity, stability and species interaction networks (Whitham et al. 2012; Gehring et al. 2014; Crutsinger 2016). Additionally, genetic variation is a driver of intraspecific variation. Some studies have now demonstrated direct and indirect genetic effects of species interactions on the composition of communities. These effects interact either through the formation of subgroups or modules for certain genotypes or through the damping of environmental effect upon the underlying genetic diversity of key species (Franks et al. 2007; Evans et al. 2008; O'Neill 2008; Keith et al. 2010). This suggested that anthropogenic and landscape variables affecting genetic diversity of key species can threaten the structure of large communities. Keith et al. (2017) found that around $85 \%$ of ecological patterns were dampened due to genetic diversity, while only $13 \%$ amplifies its effect and $8 \%$ creates new patterns.
Further, the number of empirical studies on networks is scarce and studies in the tropics that provide network structure and environmental gradients are even fewer (Alves Ferreira et al. 2013). It is, therefore, increasingly important to understand how genetic variability and environmental variables contributes to complex community properties such as diversity, interaction networks, stability, and community network structure.

Previous studies on genetic diversity and the effect of landscape on antagonist interaction network of herbivorous and plants has demonstrated that modularity increase while nestedness has a tendency to decrease (Keith et al. 2017). Further, Fortuna et al. (2010) found that there was a tendency for either nesting or modularity, but not both at the same time, to increase in highly connected networks. Yet, genetic diversity may increase the complexity of the web, the number of interaction and robustness (Barbour et al. 2016) suggesting that the genetic variation of a key species can have a strong effect on community structure. In our study $C$. pepo functions as a key species due to its evolutionary relationship with bees and its cultural relationship with traditional community practices. In particular, we expect that network structure will be affected by increasing genetic variation of pumpkin through more interactions per species and increased nestedness or modularity (Paine 1969; Fortuna et al. 2010; Barbour et al. 2016; Keith et al. 2017) and therefore greater and robust foodweb complexity as discussed above. However, whether the genetic variation can scale up to affect pollinator-plant interaction network is currently unclear and to our knowledge, this is one of the first studies analysing together genetic diversity, landscape effect on network structure. We also expect that the information generated with this study will be the basis for more in-depth analysis of the action of genetic diversity on interaction network and how it relates to landscape that can lead to the understanding and conservation of community structure.

Here, we address the following questions (1) how differences in female and male flower affect the interaction network of $C$. pepo? i.e., pollinator diversity, community and variables of network composition (modularity, nestedness, network specialisation and number of interactions), (2) does genetic diversity of $C$. pepo affect the individual-based flower-bee visitation network? and (3), what is the effect that landscape, accounting for the genetic variability of $C$. pepo, has on these variables of individual-based pumpkin flower-bee visitation network?

\section{Materials and methods}

\section{Study sites, plant sampling, DNA extraction and amplification}

We used samples already surveyed in a previous study in the Cloud Forest Corridor (CFC) (Enríquez et al. 2018), that is characterized by a high cultural and natural diversity. Seven 
cultivars of traditional $C$. pepo landraces from five sites in Baja Verapaz, Guatemala (Panzal, Repollal, Union Barrios, and Chipacay; Table S1) were sampled to obtain plant tissue for DNA extraction. Additionally, three new localities from Puruhlá in department of Baja Verapaz, in the centre of Guatemala were sampled to record individual-based $C$. pepo-visitors' interactions for a total of ten sampling sites (Fig. 1).

\section{Sampling of bees and their interactions}

Cucurbita pepo individual-based flower-visitors were recorded in ten sites during the flowering peak of $C$. pepo from April to June of 2012. We sampled flower-visiting bees that touched the reproductive parts of each female and male flower in three-minute time. Sampling was carried out for 3 days at each site to complete at least 100 female and 100 male flowers. As a result, we obtained a total of $10 \mathrm{~h}$ per site; 3 min for each of 100 female and 100 male flowers in each site, since not all flowers were visited, we obtained floral-visitors' observations for less flowers (female: mean $=59.54 \pm 22.52 \mathrm{SD}$, male: mean $=65.64 \pm 36.98 \mathrm{SD}$ ). Collected bees were stored in tubes for later identification. We collected only bees due to the extremely low number of non-bee flower-visitors observed during sampling $(<0.1 \%$ of total interactions). All bees were identified by expert taxonomists, $52 \%$ to species level and $48 \%$ to genera.

To describe bee diversity and analyse the effect of bee diversity on network structure, we used total abundance,

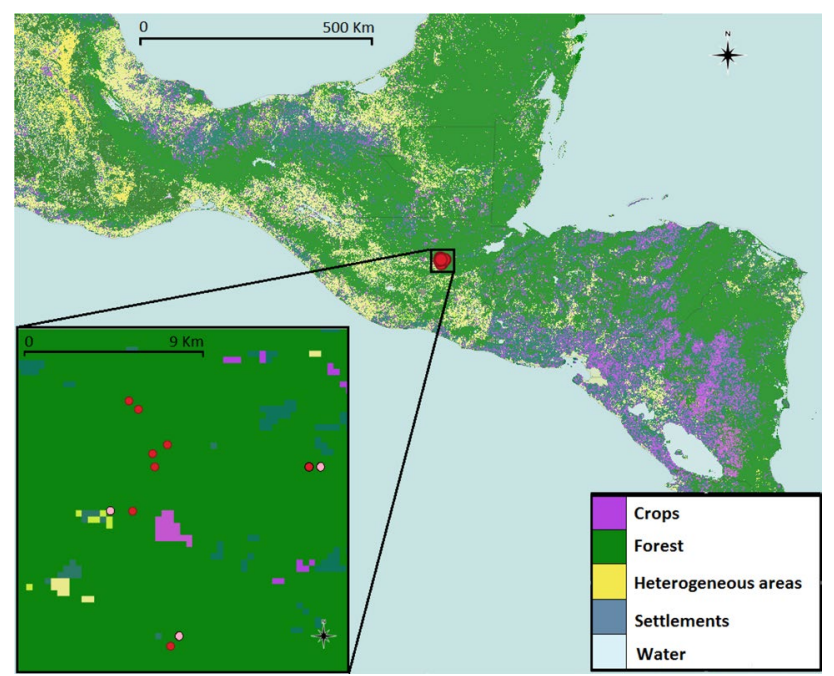

Fig. 1 Locations of study sites (pink and red circles) in the Cloud Forest Corridor (CFC) of Guatemala. The red circles are the sites for which both interaction networks and microsatellite information was obtained. The pink circles are the ones with only interaction network information. Four land use types and water presence are indicated with different colours as follow: Crop is lila, forest green, heterogeneous areas yellow, settlements blue-grey and water light blue rarefied bee richness, Shannon index and local contribution of beta diversity -LCBD- (Legrendre and Cáceres 2013) which is a comparative indicator of the ecological uniqueness of sites according to their contributions to beta diversity. Large LCBD values indicate sites that have strongly different species compositions compared with a site with lower or mean values (Legendre 2014). Additionally, we also used the abundance of the most common bees (Apis mellifera $43.55 \%$, Partamona bilineata $36.33 \%$ and Trigona silvestriana $4.07 \%$ ). The LCBD was calculated using package adespatial v0.3-8 (Dray et al. 2012), abundance data were transformed so the resulting dissimilarity assessments are ecologically meaningful with Hellinger transformation (Legendre \& Cáceres 2013).

\section{Landscape variables}

In each study site, we quantified land cover at increasing radii of 200, 300, 500 and $1000 \mathrm{~m}$ from the centre of each site. Land-use was classified in four categories: (1) forest (mostly pine-oak forests), (2) semi-natural areas (including early succession areas), (3) annual agriculture, (4) settlements (including villages and homesteads with milpa agriculture). To determine the spatial scale of bee responses to land use, we performed Spearman rank correlations between bee abundance, rarefied bee richness and Shannon diversity of bees against our four landscape categories (as in Landaverde-González et al. 2017). The correlation coefficient peaked at the $200 \mathrm{~m}$ scale for bee abundance, bee richness and Shannon Diversity Index (Table S2). Accordingly, we used the $200 \mathrm{~m}$ scale for subsequent landscape-scale analyses. Additionally, we calculated several metrics for forest fragmentation: (1) distance to the closest fragments, (2) average fragment size $\left(\mathrm{m}^{2}\right)$ and (3) percentage of fragment areas. In our downstream analyses, we only used the distance to the closest fragment and percentage of fragment areas to represent landscape fragmentation, as average fragment size was highly correlated with percentage of fragment areas $\left(r^{2}=0.95\right)$.

\section{Data analysis}

\section{Genetic data}

We used GeneMarker software v 2.4.0 (Hulce et al. 2011) to construct the allelic matrix per microsatellite assayed. We used eight microsatellite loci as selected by (Enríquez et al. 2018). For the subsequent analysis we used allele abundance (AB), allele richness (AR), observed (Ho) and expected (He) heterozygosity. To obtain the values of $\mathrm{AB}, \mathrm{AR}, \mathrm{Ho}$ and $\mathrm{He}$, the program MSA v.4.05 (Dieringer and Schlötterer 2003) was used (Table S3). To account for differences in sample sizes and genotyping success, allele rarefaction was used in 
the calculation using the package PopGenReport (Gruber and Adamack 2015).

\section{Individual-based flower visitation networks}

To investigate individual-based plant-pollinator interactions across communities, we generated flower-bee network metrics for site and for each individual female and male flower using the R package bipartite v.2.08 (Dormann et al. 2009). For each site and gender, quantitative individual-based networks (Fig. S1) were represented as a matrix in which each cell contained the frequency of pair-wise interactions between individual flower of $C$. pepo (rows) and bee morphospecies (columns).

For each matrix, we computed five network metrics: complementary network specialisation (H2'), nestedness (NODF), modularity, robustness and number of interactions per individual-pumpkin (Table 1). H2' describes the degree of specialisation of the network (Blüthgen et al. 2006). For nestedness, we used the weighted NODF metric (nestedness metric based on overlap and decreasing fill by Almeida-Neto et al. 2008) that indicates whether species with fewer partners (specialist) tend to interact with subsets of species more connected (generalist) and indicates the existence of asymmetry in plant-pollinator interactions (Bascompte and Jordano 2014). Modularity describes the tendency of different subsets of species to interact more frequently with each other than with the rest of the species in the network (Guimerà and Amaral 2005). Robustness is calculated as the area below the extinction curve generated by "second.extinct", as the measure of the ability of the system to endure species lost.

Due to the dependence of network metrics on network dimensions, we calculated a null model for each metric network and site by simulating 1000 random interaction networks, using the Patefield's algorithm (Patefield 1981) that reflect the degree to which a network metric deviates from a random expectation. Then, to obtain network metrics that are unbiased, we $\Delta$-transformed all metrics using the calculated null model (Dalsgaard et al. 2017; Schleuning et al. 2014; Simmons et al. 2018). The $\Delta$-transformed network metrics were calculated as in Escobedo-Kenefic et al. (2020).

\section{Statistical analyses}

In the present study, we used an individual-based network approach to access the effect of landscape and genetic diversity in the organisation of interactions between individuals of $C$. pepo and their flower-visitors.

First, we were interested to evaluate the difference between female and male flowers interaction networks. For that we used a paired $t$-test and chi-square test (paired by site) to analyse the differences between female and male flowers in network specialisation (H2'), nestedness (NODF), modularity, robustness and number of interactions per individual-pumpkin. Additionally, to test for differences in bee and community composition between female and male flower, we performed a paired permutational multivariate analysis of variance using the adonis function, with 999 permutations, implemented in the R package vegan $\mathrm{v}$. 2.5-7 (Oksanen et al. 2020). In the adonis analysis for bees, the Bray-Curtis distance matrix of bee species composition was the response variable, with gender (female/male) as the independent variable. The strata (block) argument was set to site so that randomisations were constrained to occur within each sample site and not across all sample sites.

Second, we evaluate if there was an effect of genetic diversity on the five network measures: network specialisation (H2'), nestedness (NODF), modularity, robustness and number of interactions per individual-pumpkin. For that, generalized linear models-GLM- with a Gaussian error structure were used. We expected to observe an increase in

Table 1 Network indices and ecological significance

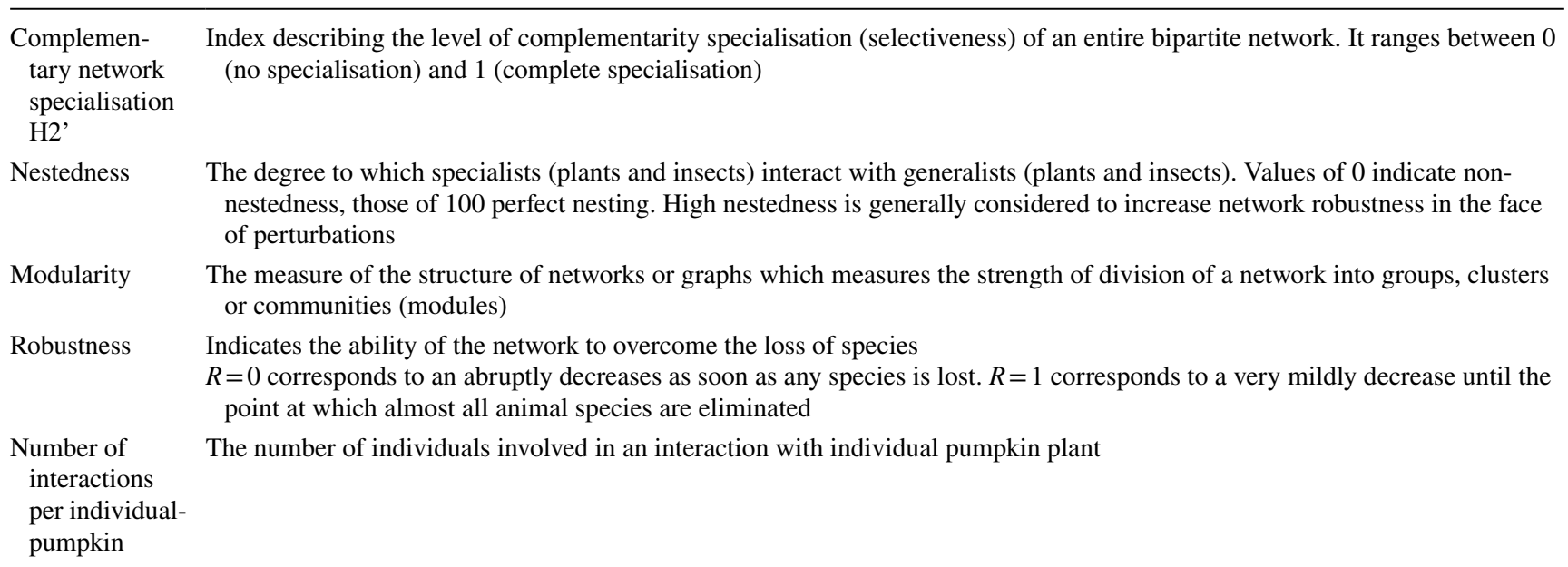


all the network measures as genetic diversity increased as commented in the introduction (Fig. 2A).

Third, we wanted to determine the effect that landscape variables, accounting for genetic diversity, have on individual-based interaction network of C. pepo. For that, mixed model analyses were performed using the $\mathrm{R}$ package lme 4 (Bates et al. 2015). Genetic data was used as a random factor due to the variability of the genetic information between sites. Landscape-scale variables were used as fixed effects. All model (GLMMs and LMMs) assumptions were checked visually and were found to conform to expectations (e.g., normality of the distribution of residuals, homogeneity of variances, linearity). We used variance inflation factors to check for collinearity among our explanatory variables. Variance inflation factors were lower than three for all predictors in all models tested, suggesting no collinearity (Zuur et al. 2009). We checked for spatial autocorrelation in our dataset using Moran's $I$ within the R package spdep (Bivand et al. 2013). No spatial autocorrelation was found in any of our statistical models $(P>0.05)$. We expected to find a positive effect (increased stability and robustness of the network structure) of forest, semi-natural areas and percentage of fragments on the network structure, while we expected that agriculture, settlement and distance to the closest fragment will have a negative effect (reduced stability and robustness of the network structure) on network structure (Fig. 2B, C).

\section{Results}

Across all sites, we recorded a total of 1667 bee individuals (a total of 27 morphospecies) visiting flowers (considering both male and female gender) of $C$. pepo individuals (Table S4; Fig. S2). The number of interactions was also 1667 as they correspond to the individual bee species observed. These interactions consisted of 860 (mean average per site $78 \pm 40.62 \mathrm{SD}$ ) interactions for female flowers and 930 (mean average per site $93 \pm 61.50 \mathrm{SD}$ ) interactions for male flowers.

\section{Differential interaction network dynamics for female and male flower}

Female flowers had the same numbers of floral visitor species (Mean \pm SD: $1.15 \pm 0.11$ species) when compared with male flowers $(1.10 \pm 0.09$ species $)(t=2.08 ; P=0.07)$ and there was no significant difference between the community composition of female and male flowers $\left(F_{1,20}=0.28\right.$, $\left.R^{2}=0.01, P=0.97\right)$. However, the abundance of pollinators for female flowers was significantly higher (Mean \pm SD: $1.52 \pm 0.26)$ compared to male flowers $(1.26 \pm 0.25)$ $(t=5.10 ; P<0.01)$.

Further, no significant difference was found in five measures of interaction network between female and male flower: network specialisation- $\mathrm{H} 2{ }^{\prime}-(t$-test $=0.84, P=0.43$; Fig. S3A), nestedness-NODF- $(t$-test $=-0.02, P=0.97$; Fig. S3B), modularity ( $t$-test $=1.11, P=0.19$; Fig. S3C), robustness $(t$-test $=2.17, P=0.06$; Fig. S3D) and number of interactions per individual-pumpkin $(t$-test $=-1.06, P=0.37$; Fig. S3E).

\section{Effect of Cucurbita pepo genetic diversity on individual-based pumpkin flower-bee visitation network}

To determine the effect of genetic diversity of $C$. pepo plants on the individual-based pumpkin-bee visitation network, we assessed the relationship of four genetic measures: allele abundance (AB), allele richness (AR), observed (Ho) and expected $(\mathrm{He})$ heterozygosity. We found that for network
Fig. 2 Diagrams showing the expectations of the action of A genetic diversity of $C$. pepo (box in blue); B Forest, seminatural areas and percentage of fragments and $\mathbf{C}$ Agriculture, settlement and distance to the closest fragment (landscape, boxes in green) on the structure of the networks
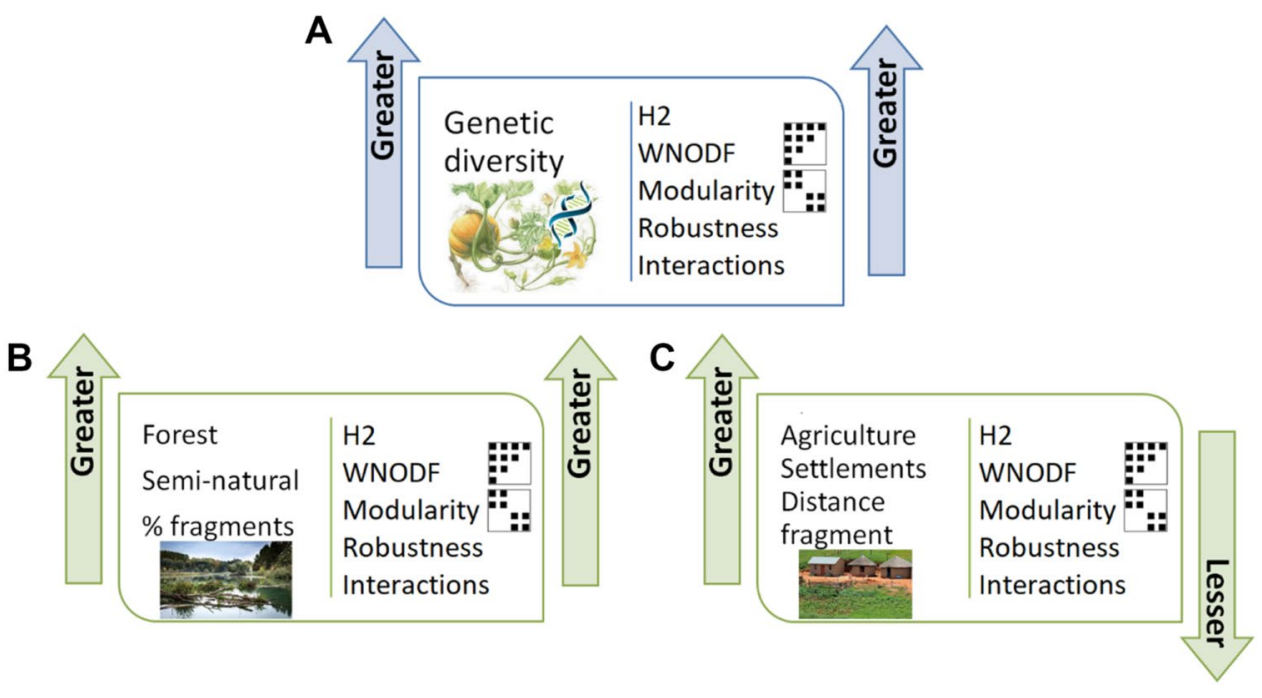
specialisation-H2'-, allele abundance $(t$-test $=-3.75$, $P=0.01-\mathrm{AB}-)$ and allele richness $(t$-test $=-2.88, P=0.01-$ AR-) have a significant negative relationship (Table 2, Fig. 3A, B respectively), that is, the greater abundance and richness of alleles, the less the specialisation of the network. For nestedness, we observed a positive significant relationship of abundance of alleles ( $t$-test $=8.69, P<0.01-\mathrm{AB}$-) and observed heterozygosity ( $t$-test $=3.3, P=0.02-\mathrm{HO}$-; Table 2, Fig. 3C, D respectively), that is, the greater the heterozygosity and abundance of alleles in C. pepo, the greater the nestedness or the degree in which specialists interact with generalists. For modularity, only allele richness ( $t$-test $=3.71, P=0.01-\mathrm{AR}$-) was found to have a significant positive effect (Table 2, Fig. 3E), meaning that the greater the allele richness, the greater the modules found in the network. For robustness, we found that observed heterozygosity ( $t$-test $=6.27, P<0.01-\mathrm{HO}$-) showed a positive significant correlation (Table 2, Fig. 3F). Finally, for number of interactions per individual-pumpkin only observed heterozygosity ( $t$ - test $=3.43, P=0.03-\mathrm{HO}-$ ) has a significant positive effect (Table 2, Fig. 3G).

\section{Effect of landscape on individual-based pumpkin-bee visitation networks}

Regarding the effect of landscape on individual-based Cucurbita pepo-bee visitation networks, we found different relationships for all network measures. Genetic diversity had a strong effect on the structure of the network; therefore, we analyse the effect of landscape controlling for genetic diversity of $C$. pepo on the visitation network. We do not find an effect of landscape on network specialisation- $-\mathrm{H} 2$ '-, robustness and modularity $(P>0.1)$. While for
nestedness-NODF- we found a positive significant effect of the presence of semi-natural areas $(P=0.03$; Table 3 and Fig. 4A) and forest show a marginal positive significant relationship ( $P=0.09$; Table 3$)$, while forest has a positive effect on the number of interactions per individual-pumpkin $(P=0.04$; Table 3 and Fig. 4B). Moreover, the positive effect of semi-natural areas on nestedness seems to be favoured when genetic diversity is high, while with low genetic diversity and more semi-natural areas it may be negatively affected.

\section{Discussion}

In this study, we were interested to understand how differences in female and male flower affect the interaction network of $C$. pepo and how genetic diversity and landscape can change the structure of interaction network. The results confirmed the following: (i) female and male flowers possess the same community composition and network structure. (ii) Genetic diversity has a varied significant relationship with the measures of network structure and (iii) landscape variables also can have a significant relationship with some network attributes that seems to be enhanced or buffered by genetic diversity.

\section{Interaction network and bee diversity on C. pepo female and male flower}

There were no differences in diversity, flower-visitor community composition or interaction network dynamic between female and male flowers, although there was a difference in the abundance of pollinators between both. This suggests
Table 2 Generalized linear model explaining the effect of genetic diversity on the measures of network structure across all sampling sites

\begin{tabular}{|c|c|c|c|c|c|c|}
\hline & Estimate Std & Error & $\mathrm{DF}$ & $t$ value & $\operatorname{Pr}(>|t|)$ & \\
\hline \multicolumn{7}{|l|}{$\Delta \mathrm{H} 2^{\prime}$} \\
\hline Allele abundance $C$. pepo & -0.02 & $<0.01$ & 4 & -3.75 & 0.01 & $*$ \\
\hline Richness alleles C. реро & -0.07 & 0.03 & 4 & -2.88 & 0.04 & $*$ \\
\hline \multicolumn{7}{|l|}{$\Delta \mathrm{NODF}$} \\
\hline Allele abundance $C$. pepo & 1.88 & 0.22 & 4 & 8.69 & $<0.01$ & $* * *$ \\
\hline Hobs $C$. pepo & 204.4 & 61.89 & 4 & 3.3 & 0.02 & $*$ \\
\hline \multicolumn{7}{|l|}{$\Delta$ Modularity } \\
\hline Richness alleles C. реро & 0.06 & 0.02 & 4 & 3.71 & 0.01 & $*$ \\
\hline \multicolumn{7}{|l|}{$\Delta$ Robustness } \\
\hline Hobs C. pepo & 0.28 & 0.04 & 4 & 6.27 & $<0.01$ & $*$ \\
\hline \multicolumn{7}{|l|}{ Interaction per individual } \\
\hline Hobs C. реро & 345.07 & 100.62 & 4 & 3.43 & 0.03 & $*$ \\
\hline
\end{tabular}

$\Delta$-transformed $\mathrm{H}^{\prime}{ }^{\prime}=$ Network specialisation; $\Delta$-transformed NODF $=$ Nestedness (the degree to which specialists interact with generalists); $\Delta$-transformed Modularity (the strength of division of a network into groups); $\Delta$-transformed Robustness (the ability of the network to overcome the loss of species) and Number of interactions per individual pumpkin

$* P<0.05, * * P<0.01 ; * * * P<0.001$ 
Fig. 3 Relationship between genetic diversity of $C$. pepo ( $A B$ Allele abundance, $A R$ allele richness and $\mathrm{HO}$ observed heterozygosity) and four measures of network structure: A, B Network specialisation ( $\Delta$-transformed H2'); C, D Nestedness ( $\Delta$-transformed NODF; the degree to which specialists interact with generalists); $\mathbf{E} \Delta$-transformed Modularity (the strength of division of a network into groups); $\mathbf{F}$ $\Delta$-transformed Robustness (the ability of the network to overcome the loss of species) and $\mathbf{G}$ Number of interactions per individual pumpkin. Means $\pm S E$ are shown; $* P<0.05, * * P<0.01$; $* * * P<0.001$. Plotted lines show predicted relationships, and the shaded areas indicate $95 \%$ confidence intervals
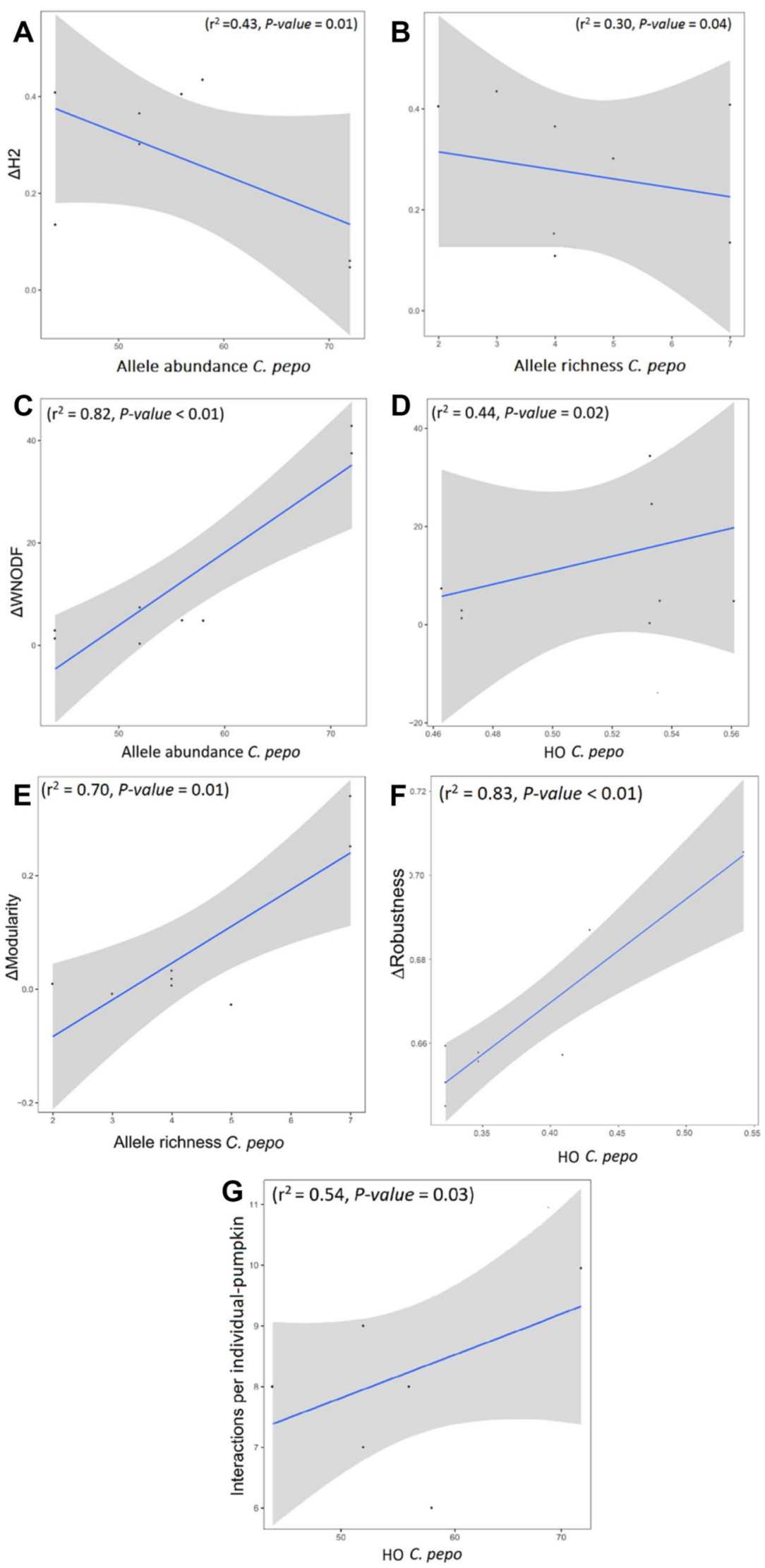
Table 3 Linear mixed effect models explaining the relationship between landscape and two network structures measures (A) $\Delta$-transformed nestedness $(\triangle \mathrm{NODF})$ and $(\mathrm{B})$ Number of interactions per individual pumpkin across all our sampling sites

\begin{tabular}{lccccc}
\hline & Value & Std. error & DF & $t$-value & $\operatorname{Pr}(>|t|)$ \\
\hline $\begin{array}{l}\text { (A) } \Delta \text { NODF } \\
\text { Forest }\end{array}$ & & & & \\
Semi-natural & 27.23 & 9.04 & 2 & 3.01 & 0.09 \\
(B) Interaction per individual & 97.36 & 18.23 & 2 & 5.34 & 0.03 \\
Forest & 2.73 & 0.58 & 2 & 4.68 & $*$ \\
\hline
\end{tabular}

$P<0.1, * P<0.05, * * P<0.01 ; * * * P<0.001$
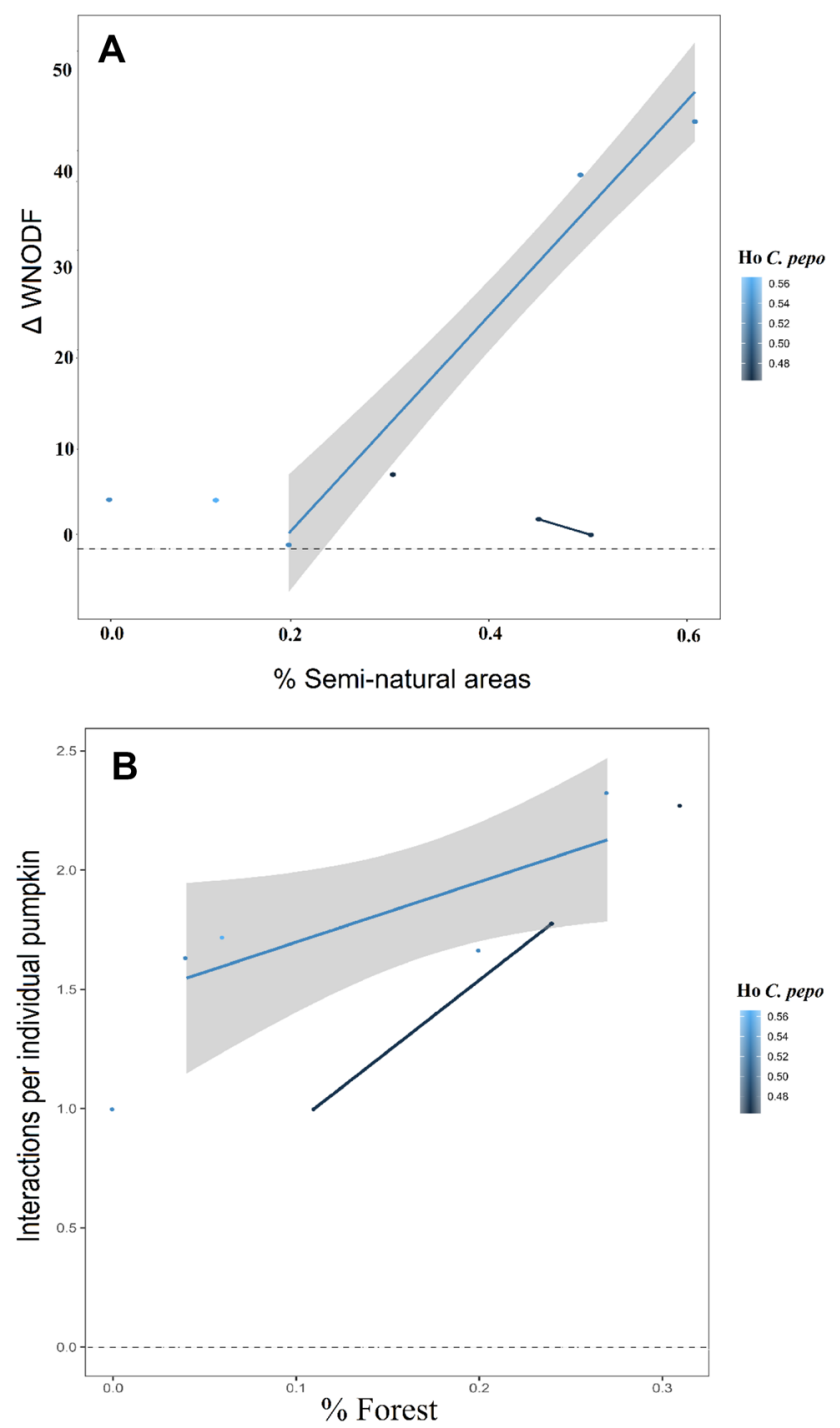

Fig. 4 Relationship between landscape variables and two measures of network structures. A Nestedness ( $\Delta$-transformed NODF; the degree to which specialists interact with generalists) and $\mathbf{B}$ number of interactions per individual pumpkin across all our sampling sites. Genetic diversity is shown by two lines of different colour. Higher genetic diversity is shown as a blue line, while lower genetic diversity is shown as a black line. Means \pm SE are shown; ${ }^{*} P<0.05, * * P<0.01$; $* * * P<0.001$. Plotted lines show predicted relationships and the shaded areas indicate $95 \%$ confidence intervals that even when there is evidence of changes in inbreeding depression, fragrance, nectar amount and abundance of flower visitor between both flower types, this does not cause a significant differential effect on their individualbased interaction network probably because they are buffered by the same plants. This buffer effect may be either due to the differences in flower time production (male are produced first) or because pollinators species did not discriminate between different levels of fragrance or nectar between flower (Ashworth and Galetto 2002), preventing any unfavourable effect on the male flowers from affecting the female flowers (Theis et al. 2009). In the same way, the abundance of floral visitors is considered a positive condition that favours the persistence of the species (Winfree et al. 2014), increasing whole plant fitness and not of individual flowers. Similarly, Dáttilo et al. (2015) found that forest fragmentation did not affect the structure of individual female and male flowers of Astrocaryum mexicanum (Arecaceae), which suggest stability of the network.

Hayes et al. (2005) suggest that differences in inbreeding depression between both types of flowers do not have a significant effect on the evolution of the reproductive system used by $C$. pepo, probably because the total inbreeding depression was under 0.5 , which is the limit for a change in the reproductive system (Rausher and Chang 1999), permitting the evolution of a stable mixed-mating reproductive system. Further, it has been observed that high temperature can also increase the number of male flowers and therefore the dynamic of flower-visitors (Wien et al. 2002), suggesting that climate change may threaten the conservation of interactions between flower visitor and C. pepo. Additionally, whether these differential dynamics between males and females' flowers have any effect on pollination is a question that is beyond the scope of this manuscript but still needs to be examined carefully.

\section{Effect of genetic diversity on individual-based pumpkin-bee visitation network}

Genetic diversity of a key species ( $C$. pepo) has a negative relationship with network specialisation. A decrease 
of network specialisation when genetic diversity increases suggest that greater diversity from the plant may allow for more varied traits that may attract an increased diversity of flower-visitor and therefore upsurge generalisation. Similar findings were observed for the rise in generalisation of a network of gall-parasitoid interactions (Barbour et al. 2016). Conversely, nestedness, modularity and number of interactions per individual-pumpkin were positively related with genetic diversity, suggesting that $C$. pepo genetic diversity is a positive attribute to maintain the robustness of the interaction network. Both nestedness and modularity have been shown to provide benefits for the stability of networks structure (Fortuna et al. 2010). Nestedness reduce effective interspecific competition and enhance the number of coexisting species (Bastolla et al. 2009), while modularity can be key to isolate perturbations in the web maintaining its stability (Thébault and Fontaine, 2010). Consequently, our results are in line with previous studies that demonstrated through combining empirical and simulated data that modularity, nestedness and co-occurrence increase as genotypic variation increased in networks of interacting key species genotypes (Lau et al. 2016).

With regards to the number of interactions, Barbour et al. (2016) found that an increase of genetic diversity also increases the number of interactions per genotype and the complexity of the network predicting a more robust to species extinctions network (Crutsinger et al. 2006; Barbour et al. 2016, 2020). Previous studies found a common pattern in which plant populations with higher genetic diversity harbour more species-rich food webs (Crutsinger 2016; Barbour et al. 2020). The theory is that the influence of genotype variation forms modules for each different genotype that increase interaction within the same modules, increasing at the same time connectance between species (Lau et al. 2016). However, the exact mechanism that allows greater genetic diversity to have a positive effect on networks is unknown. One possible explanation could be that the higher proportion of genetic diversity translates into abundant phenotypic variation allowing a greater diversity of visitors (Barbour et al. 2020). Given that we used a neutral marker (microsatellites), it's complex to determine how its variation is related to phenotypic traits chosen by floral visitors. The use of genomics, can provide a better resolution on the genetic mechanism behind trait variability and, therefore, its influence on network structure. On the other hand, intraspecific diversity can increase connectance and nestedness but decrease stability and change the interaction strength and network specialisation (Vázquez et al. 2009; Noto and Gouhier 2020). The reason for this variation in the response of the networks is competition within genotypes; if it is stronger within the genotypes, trophic networks are generally more stable, suggesting that in our study competition may occur at the intragenotypic level since we found a positive effect of genetic diversity on nestedness, modularity, robustness and number of interactions. However, in our study, we use genetic data sets for populations and thus it was not possible to obtain information on the flower-visitor for each specific genotype that would allow a better understanding of the dynamics between and within genotypes and therefore how they affect the structure of the network.

\section{Effect of landscape on individual-based pumpkin-bee visitation network}

The presence of semi-natural areas, which represented heterogeneous land, did present a significant positive relationship with nestedness and the presence of forest has a positive relationship with the number of interactions per individual-pumpkin. Similarly, previous studies in the highlands of Guatemala showed a significant positive effect of dry seasons on nestedness, suggesting the existence of niche partitioning as a result of competition for heterogeneous but scarce resources (Escobedo-Kenefic et al. 2020). Further, the cloud forest area is characterized by a lower proportion of deforestation (Enríquez et al. 2018), so the resources may not be scarce, and thus the reason why we didn't find direct negative effects from the landscape. Other studies suggested that landscape heterogeneity and native vegetation may favour bigger, more complex, robust, connected and nested networks across all scales or hierarchy levels compared to those from agricultural lands that have been documented to be negative (Adedoja and Kehinde 2018). This underscores the ecological importance of heterogeneous land and natural vegetation for the conservation of insect-flower interactions even in highly fragmented landscapes in the tropics (Alves Ferreira et al. 2013; Moreira et al. 2015, 2018). Moreover, we found a possible interaction between genetic diversity and how semi-natural areas affect nestedness, greater genetic diversity allows greater nestedness even with fewer seminatural areas, but when there is lower genetic diversity, nestedness decreases even with larger semi-natural areas. This is contrary to a study on tri-trophic interaction which showed that, although plant genetic effects were stronger across all trophic levels, these effects were transmitted independently suggesting that plant genetics did not interact with the effect of the environment analysed on network interactions (Abdala-Roberts and Mooney 2013).

Additionally, cultural management has already showed to be a variable having a significant effect on genetic diversity of $C$. pepo (Enríquez et al. 2018). In our study management was the same for all the sites, so it was not possible to analyse its effect on the interaction networks. Thus, the type of management can also have a strong effect on how genetic diversity and interaction network are structured and 
future studies considering cultural management should be included.

\section{Conclusion and future studies}

We do not find any difference in the network structure between female and male flowers, however how the difference in the amount of nectar and floral fragrance of both types of flowers affects pollination in $C$. pepo is still an open question and future analyses are necessary. While a genetic basis to community stability has previously been shown, this is one of the first studies empirically suggesting that genetic diversity may have an interaction with the landscape that enhances network structure and it may mitigate the negative effects of the environment. This establishes a caveat since the loss of important genotypes due to habitat loss and climate change may introduce instability, reducing the complexity of the network and hence also the robustness. In this way, considering the interactions of species based on genetic diversity will allow us to better understand how networks are affected by environmental and internal variables and promote diversity and stability of community networks. Our study set the bases for future studies on $C$. pepo, determining the effect of landscape, management and genetic diversity in their interaction networks. Additionally, studies in which the flower-visitors for specific genotypes can be established are crucial for a detailed understanding of the action of genetic diversity on network structure. Further, the use of genomics tools will allow having a deep understanding of the genetic dynamic related to phenotypic variation and therefore the influence on network structure and landscape effect. Likewise, more in-depth and empirical studies are needed in order to have a better understanding of the dynamics between landscape and the genetic diversity of key species on network structure.

Supplementary Information The online version contains supplementary material available at https://doi.org/10.1007/s11829-021-09872-y.

Acknowledgements We thank the administrative staff and the forest guard of the Quetzal Conservation Biotope in Baja Verapaz, Guatemala for translation from Spanish to maya Q'eqchi' languages; and we thank all the farmers in the area of Cloud Forest Corridor that allowed us to develop the Cucurbita crops to carry out the studies. We are grateful for the help and assistance in identifying bee specimens provided by Mabel Vásquez. This project could not have been done without the hard work and dedication provided by field assistant Raquel Lima, Natalia Escobedo, Carmen Yurrita, Mabel Vásquez, Gabriela Armas, María Fernanda Bracamonte, Elizabeth Solórzano, and Martín Rangel. We thank Raquel Lima, Elizabeth Solórzano and Rosalinda Tapia for their help and assistance in the laboratory for microsatellite analysis of Cucurbita. Dauno Chew at the Centro de Datos para la Conservación, Centro de Estudios Conservacionistas -CECON- is thanked for support conducting the analyses to obtain the landscape metrics.
Author contributions PL-G: Conceptualization, Funding acquisition, Formal analysis, Investigation, Methodology, Visualization, WritingOriginal draft and visualization; Writing-Review \& editing. EE: Data curation, Funding acquisition, Methodology, Project administration, Writing-Review \& editing. JN-F: Funding acquisition, Supervision, Writing-Review \& editing. All co-authors have seen, consent and approved the manuscript.

Funding Open Access funding enabled and organized by Projekt DEAL. Financial support for this project was provided by the Science and Technology National Fund of Guatemala (FODECYT 15-2011 and FODECYT 26-2012) granted to E.E; and from the Laboratory of Ecological Genetics and Evolution, Institute of Ecology, National Autonomous University of Mexico UNAM from JNF.

Availability of data and materials The data is proportionated as supplementary material.

\section{Declarations}

Conflicts of interest The authors declare that they have no conflict of interests.

Ethical approval This article does not contain any experiment on human or animal performed by any of the authors.

Open Access This article is licensed under a Creative Commons Attribution 4.0 International License, which permits use, sharing, adaptation, distribution and reproduction in any medium or format, as long as you give appropriate credit to the original author(s) and the source, provide a link to the Creative Commons licence, and indicate if changes were made. The images or other third party material in this article are included in the article's Creative Commons licence, unless indicated otherwise in a credit line to the material. If material is not included in the article's Creative Commons licence and your intended use is not permitted by statutory regulation or exceeds the permitted use, you will need to obtain permission directly from the copyright holder. To view a copy of this licence, visit http://creativecommons.org/licenses/by/4.0/.

\section{References}

Abdala-Roberts L, Mooney KA (2013) Environmental and plant genetic effects on tri-trophic interactions. Oikos 122:1157-1166

Adedoja O, Kehinde T (2018) Changes in interaction network topology and species composition of flower-visiting insects across three land use types. Afr J Ecol 56:964-971

Aguilar J, Illsley C, Marielle C (2003) Los sistemas agricolas de maiz y sus procesos técnicos. In: Esteva G, Marielle C (eds) Sin maíz no hay país. CONACULTA, Mexico City, pp 83-122

Almeida-Neto M, Guimarães PRJ, Loyola RD, Ulrich W (2008) A consistent metric for nestedness analysis in ecological systems: reconciling concept and measurement. Oikos 117:1227-1239

Alves Ferreira P, Boscolo D, Viana BF (2013) What do we know about the effects of landscape changes on plant-pollinator interaction networks? Ecol Indic 31:35-40

Ashworth L, Galetto L (2002) Differential nectar production between male and female flowers in a wild cucurbit: Cucurbita maxima sp. andreana (Cucurbitaceae). Can J Bot 80:1203-1208. https://doi. org/10.1139/b02-110 
Barbour MA, Fortuna MA, Bascompte J, Nicholson JR, Julkunen-Tiitto R, Jules ES, Crutsinger GM (2016) Genetic specificity of a plantinsect food web. PNAS 113:2128-2133

Barbour A, Kliebenstein DJ, Bascompte J (2020) Genetic diversity increases food-web persistence in the face of climate warming. bioRxiv. https://doi.org/10.1101/2020.06.23.167387

Bascompte J, Jordano P (2014) Mutualistic networks. Princeton University Press, Princeton

Bastolla U, Fortuna MA, Pascual-García A, Ferrera A, Luque B, Bascompte J (2009) The architecture of mutualistic networks minimizes competition and increases biodiversity. Nature 458:1018-1020

Bates D, Mächler M, Bolker B, Walker S (2015) Fitting linear mixed effects models using lme4. J Stat Softw 67:1-48

Bivand R, Hauke J, Kossowski T (2013) Computing the jacobian in gaussian spatial autoregressive models: an illustrated comparison of available methods. Geogr Anal 45:150-179

Blüthgen N, Menzel F, Blüthgen N (2006) Measuring specialization in species interaction networks. BMC Ecol 6:9

Casas A, Otero-Arnaiz A, Pérez-Negrón E, Valiente-Banuet A (2007) In situ management and domestication of plants in Mesoamerica. Ann Bot 100:1101-1115

Castellanos-Morales G, Ruiz-Mondragón KY, Hernández-Rosales HS, Sánchez-de la Vega G, Gámez N, Aguirre-Planter E, Montes-Hernández S, Lira-Saade R, Eguiarte LE (2019) Tracing back the origin of pumpkins (Cucurbita pepo ssp. pepo L.) in Mexico. Proc R Soc B 286:20191440

Castellanos-Morales G, Paredes-Torres LM, Gámez N, Hernández-Rosales HS, Sánchez-de la Vega G, Barrera-Redondo J, Aguirre-Planter E, Vázquez-Lobo A, Montes-Hernández S, Lira-Saade R, Eguiarte LE (2018) Historical biogeography and phylogeny of cucurbita: insights from ancestral area reconstruction and niche evolution. Mol Phylogenet Evol 128:38-54

Crutsinger GM, Collins MD, Fordyce JA, Gompert Z, Nice CC, Sanders NJ (2006) Plant genotypic diversity predicts community structure and governs an ecosystem process. Science 18:966-968

Crutsinger GM (2016) A community genetics perspective: opportunities for the coming decade. New Phytol 210:65-70

Dalsgaard B, Schleuning M, Maruyama PK, Dehling DM, Sonne J, Vizentin-Bugoni J, Zanata TB, Fjeldså J, Böhning-Gaese K, Rahbek C (2017) Opposed latitudinal patterns of network derived and dietary specialisation in avian plant-frugivore interaction systems. Ecography 40:1395-1401

Dalsgaard B (2020) Land-use and climate impacts on plant-pollinator interactions and pollination services. Diversity 12:168

Dáttilo W, Aguirre A, Quesada M, Dirzo R (2015) Tropical forest fragmentation affects floral visitors but not the structure of individualbased palm-pollinator networks. PLoS ONE 10:e0121275

Dieringer D, Schlötterer C (2003) Microsatellite analyser (MSA): a platform independent analysis tool for large microsatellite data sets. Mol Ecol Notes 3:167-169

Dormann CF, Frund J, Blüthgen N, Gruber B (2009) Indices, graphs and null models: analyzing bipartite ecological networks. Open Ecol J 2:7-24

Dray S, Pélissier R, Couteron P, Fortin M, Legendre P, Peres-Neto PR, Bellier E, Bivand R, Blanchet FG, De Cáceres M, Dufour A, Heegaard E, Jombart T, Munoz F, Oksanen J, Thioulouse J, Wagner HH (2012) Community ecology in the age of multivariate multiscale spatial analysis. Ecol Monogr 82:257-275. https://doi. org/10.1890/11-1183.1

Enríquez E, Landaverde P, Lima R, Núñez-Farfán J, Solórzano E, Tapia-López R (2018) Genetic erosion of traditional landraces of Cucurbita pepo (Cucurbitaceae) in Baja Verapaz, Guatemala. Genet Resour Crop Ev 65:979-991
Escobedo-Kenefic N, Landaverde-González P, Theodorou P, Cardona E, Dardón MJ, Martínez O, Domínguez CA (2020) Disentangling the effects of local resources, landscape heterogeneity and climatic seasonality on bee diversity and plant-individual-based flowervisitor networks in tropical highlands. Oecologia 194:333-344

Evans LM, Allan GJ, Shuster SM, Woolbright SA, Whitham TG (2008) Tree hybridization and genotypic variation drive cryptic speciation of a specialist mite herbivore. Evolution 62:3027-3040

Franks SJ, Sim S, Weis AE (2007) Rapid evolution of flowering time by an annual plant in response to a climate fluctuation. PNAS 104:1278-1282

Fortuna MA, Stouffer DB, Olesen JM, Jordano P, Mouillot D, Krasnov BR, Poulin R, Bascompte J (2010) Nestedness versus modularity in ecological networks: two sides of the same coin? J Anim Ecol 79:811-817

Gehring C, Flores-Rentería D, Sthultz CM, Leonard TM, FloresRentería L, Whipple AV, Whitham TG (2014) Plant genetics and interspecific competitive interactions determine ectomycorrhizal fungal community responses to climate change. Mol Ecol 23:1379-1391

Gliessman SR (1983) Allelopathic interactions in crop-weed mixtures: applications for weed management. Manag J Chem Ecol 9:991-999

Gong L, Paris HS, Stift G, Pachner M, Vollmann J, Lelley T (2013) Genetic relationships and evolution in Cucurbita as viewed with simple sequence repeat polymorphisms: the centrality of $C$. okeechobeensis. Genet Resour Crop Evol 60:1531-1546

Gruber B, Adamack AT (2015) Landgenreport: a new R function to simplify landscape genetic analysis using resistance surface layers. Mol Ecol Resour 15:1172-1178

Guimerà R, Amaral LAN (2005) Cartography of complex networks: modules and universal roles. J Stat Mech 2005:P02001

Hayes CN, Winsor JA, Stephenson AG (2005) A comparison of male and female responses to inbreeding in Cucurbita pepo subsp. texana (Cucurbitaceae). Am J Bot 92:107-115

Hulce D, Li X, Snyder-Leiby T, Johathan Liu CS (2011) GeneMarker® Genotyping Software: tools to increase the statistical power of DNA fragment analysis. J Biomol Tech 22:S35-S36

Keith AR, Bailey JK, Whitham TG (2010) A genetic basis to community repeatability and stability. Ecology 91:3398-3406

Keith AR, Bailey JK, Lau MK, Whitham TG (2017) Genetics-based interactions of foundation species affect community diversity, stability and network structure. Proc R Soc B 284:20162703

Khoury CK, Achicanoy HA, Bjorkman AD, Navarro-Racines C, Guarino L, Flores-Palacios X, Engels J, Wiersema JH, Dempewolf $\mathrm{H}$, Sotelo S, Ramírez-Villegas J, Castañeda-Álvarez NP, Fowler C, Jarvis A, Rieseberg LH, Struik PC (2016) Origins of food crops connect countries worldwide. Proc R Soc B 283:20160792

Landaverde-González P, Quezada-Euán J, Theodorou P, Murray T, Ayala R, Moo-Valle J, Husemann M, Vandame R, Paxton R (2017) Sweat bees on hot chillies: provision of pollination services by native bees in traditional slash-and-burn agriculture in the Yucatan Peninsula of tropical Mexico. J Appl Ecol 54:1814-1824

Lau MK, Keith AR, Borrett SR, Shuster SM, Whitham TG (2016) Genotypic variation in foundation species generates network structure that may drive community dynamics and evolution. Ecology 97:733-742

Legendre P, De Cáceres M (2013) Beta diversity as the variance of community data: dissimilarity coefficients and partitioning. Ecol Lett 16:951-963

Legendre P (2014) Replacement and richness difference components. Glob Ecol Biogeogr 23:1324-1334. https://doi.org/10.1111/geb. 12207

Lozada-Aranda M, Rojas Barrera I, Mastretta Yanes A, Ponce-Mendoza A, Burgeff C, Orjuela-R OMA (2017) Las milpas de Mexico. Oikos 17:10-12 
Moreira EF, Boscolo D, Viana BF (2015) Spatial heterogeneity regulates plant-pollinator networks across multiple landscape scales. PLoS ONE 10:1-19

Moreira EF, Ferreira PA, Lopes LE, Gomes S, Boscolo D (2018) Ecological networks in the changing tropics. In: Dáttilo W, Rico-Gray $\mathrm{V}$ (eds) Ecological networks in the tropics. Springer, Cham

Noto AE, Gouhier TC (2020) The effects of intraspecific and interspecific diversity on food web stability. Theor Ecol 13:399-407

O'Neill GA (2008) Accounting for population variation improves estimates of the impact of climate change on species' growth and distribution. J Appl Ecol 45:1228-1236

Oksanen J, Blanchet FG, Kindt R, Legendre P, Minchin PR, O'Hara RB, Simpson GL, Solymos P, Henry M, Stevens H, Wagner H (2020) vegan: Community Ecology Package.

Organization for Economic Co-operation and Development OECD (2012) Consensus document on the biology of Cucurbita L. (squashes, pumpkins, zucchinis, and gourds). Series on harmonization of regulatory oversight in biotechnology. OECD, Paris

Paine RT (1969) A note on trophic complexity and community stability. Am Nat 103:91-93

Paris HS, Yonash N, Portnoy V, Mozes-Daube N, Tzuri G, Katzir N (2003) Assessment of genetic relationships in Cucurbita pepo (Cucurbitaceae) using DNA markers. Theor Appl Genet 106:971-978

Paris HS, Lebeda A, Kristovka E, Andres TC, Nee MH (2012) Parallel evolution under domestication and phenotypic differentiation of the cultivated subspecies of Cucurbita pepo (Cucubitaceae). Econ Bot 66:71-90

Paris HS (2016) Genetic resources of pumpkins and squash Cucurbita spp. In: Grumet R, Katzir N, Garcia-Mas J (eds) Genetics and genomics of Cucurbitaceae Plant genetics and genomics: crops and models series, vol 20. Springer, Cham, pp 61-86

Patefield WM (1981) Algorithm AS 159: an efficient method of generating random $\mathrm{R} \times \mathrm{C}$ tables with given row and column totals. $\mathrm{J}$ R Stat Soc C-Appl 30:91-97

Rausher MD, Chang SM (1999) Stabilization of mixed-mating systems by differences in the magnitude of inbreeding depression for male and female fitness components. Am Nat 154:242-248

Sanchez-de la Vega G, Castellanos-Morales G, Gamez N, HernandezRosales HS, Vazquez-Lobo A, Aguirre-Planter E, Jaramillo-Correa JP, Montes-Hernández S, Lira-Saade R, Eguiarte LE (2018)
Genetic resources in the "Calabaza Pipiana" squash (Cucurbita argyrosperma) in Mexico: genetic diversity, genetic differentiation and distribution models. Front Plant Sci 9:1-18

Schleuning M, Ingmann L, Strauß R, Fritz SA, Dalsgaard B, Dehling DM, Plein M, Saavedra F, Sandel B, Svenning JC, Böhning-Gaese K, Dormann CF (2014) Ecological, historical and evolutionary determinants of modularity in weighted seed-dispersal networks. Ecol Lett 17:454-463

Simmons BI, Sutherland WJ, Dicks LV, Albrecht J, Farwig N, García D, Jordano P, González-Varo JP (2018) Moving from frugivory to seed dispersal: incorporating the functional outcomes of interactions in plant-frugivore networks. J Anim Ecol 87:995-1007

Thébault E, Fontaine C (2010) Stability of ecological communities and the architecture of mutualistic and trophic networks. Science 329:853-856

Theis N, Kesler KL, Adler S (2009) Leaf herbivory increases floral fragrance in male but not female Cucurbita pepo subsp. Texana (Cucurbitaceae) flowers. Am J Bot 96:897-903

Vázquez DP, Chacoff NP, Cagnolo L (2009) Evaluating multiple determinants of the structure of plant-animal mutualistic networks. Ecology 90:2039-2046

Whitham TG, Gehring CA, Lamit LJ, Wojtowicz T, Evans LM, Keith AR, Smith DS (2012) Community specificity: life and afterlife effects of genes. Trends Plant Sci 17:271-281

Wien HC, Stapleton SC, Maynard DN, McClurg C, Nyankanga R, Riggs D (2002) Regulation of female flower development in pumpkin (Cucurbita spp.) by temperature and light. In: Maynard DN (ed) Cucurbitaceae. ASHS Press, Alexandria, pp 307-315

Winfree R, Williams NM, Dushoff J, Kremen C (2014) Species abundance, not diet breadth, drives the persistence of the most linked pollinators as plant-pollinator networks disassemble. Am Nat 183:600-611

Zuur A, Ieno EN, Walker N, Saveliev AA, Smith GM (2009) Mixed effects models and extensions in ecology with R. Springer-Verlag, New York

Publisher's Note Springer Nature remains neutral with regard to jurisdictional claims in published maps and institutional affiliations. 